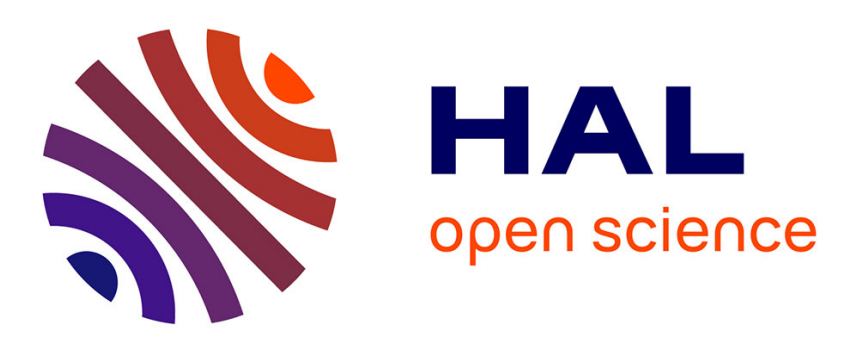

\title{
Modeling growth of three bakery product spoilage molds as a function of water activity, temperature and $\mathrm{pH}$.
} Stephane Dagnas, Bernard Onno, Jeanne Marie J. M. Membré

\section{To cite this version:}

Stephane Dagnas, Bernard Onno, Jeanne Marie J. M. Membré. Modeling growth of three bakery product spoilage molds as a function of water activity, temperature and $\mathrm{pH}$.. International Journal of Food Microbiology, 2014, 186, pp.95-104. 10.1016/j.ijfoodmicro.2014.06.022 . hal-02638021

\section{HAL Id: hal-02638021 https://hal.inrae.fr/hal-02638021}

Submitted on 28 May 2020

HAL is a multi-disciplinary open access archive for the deposit and dissemination of scientific research documents, whether they are published or not. The documents may come from teaching and research institutions in France or abroad, or from public or private research centers.
L'archive ouverte pluridisciplinaire HAL, est destinée au dépôt et à la diffusion de documents scientifiques de niveau recherche, publiés ou non, émanant des établissements d'enseignement et de recherche français ou étrangers, des laboratoires publics ou privés. 


\title{
Modeling growth of three bakery product spoilage molds as a function of water activity, temperature and $\mathrm{pH}$
}

\author{
Stéphane Dagnas a , Bernard Onno a, Jeanne-Marie Membré ${ }^{\mathrm{b}, \mathrm{a}, *}$ \\ a L'Université Nantes Angers Le Mans, Oniris, Nantes F-44322 Cedex 3, France \\ b Institut National de la Recherche Agronomique, UMR1014 Sécurité des Aliments et Microbiologie, Nantes F-44307, France
}

\section{A R T I C L E I N F O}

\section{Article history:}

Received 4 November 2013

Received in revised form 7 April 2014

Accepted 21 June 2014

Available online 28 June 2014

\section{Keywords:}

Predictive microbiology

Mold spoilage

Bakery product

Bayesian statistics

Shelf-life

\begin{abstract}
A B S T R A C T
The objective of this study was to quantify the effect of water activity, $\mathrm{pH}$ and storage temperature on the growth of Eurotium repens, Aspergillus niger and Penicillium corylophilum, isolated from spoiled bakery products. Moreover, the behaviors of these three mold species were compared to assess whether a general modeling framework may be set and re-used in future research on bakery spoilage molds. The mold growth was modeled by building two distinct Gamma-type secondary models: one on the lag time for growth and another one on the radial growth rate. A set of 428 experimental growth curves was generated. The effect of temperature $\left(15-35{ }^{\circ} \mathrm{C}\right)$, water activity (0.80-0.98) and $\mathrm{pH}(3-7)$ was assessed. Results showed that it was not possible to apply the same set of secondary model equations to the three mold species given that the growth rate varied significantly with the factors $\mathrm{pH}$ and water activity. In contrast, the temperature effect on both growth rate and lag time of the three mold species was described by the same equation. The equation structure and model parameter values of the Gamma models were also compared per mold species to assess whether a relationship between lag time and growth rate existed. There was no correlation between the two growth responses for $E$. repens, but a slight one for A. niger and P. corylophilum. These findings will help in determining bakery product shelf-life and guiding future work in the predictive mycology field.
\end{abstract}

(c) 2014 Elsevier B.V. All rights reserved.

\section{Introduction}

Mold spoilage of bakery products causes great economic losses, estimated globally to one to three percent volume (Malkki and Ravha, 1978). The molds frequently involved are Penicillium, Aspergillus, Eurotium and Wallemia species (Dantigny et al., 2005b; Vytrasova et al., 2002).

Mold spoilage results from the contamination of a product with fungal spores, which further, if the conditions are appropriate, may germinate and form a visible mycelium before the time of consumption (Dagnas and Membré, 2013; Gougouli et al., 2011; Horner and Anagnostopoulos, 1973). Generally, mold growth can be prevented by the application of the hurdle technology concept (Leistner, 2000). Among the preservative factors water activity $\left(a_{\mathrm{w}}\right)$ is often reported as the most effective one on inhibiting mold growth (Pitt and Hocking, 1977; Sautour et al., 2001a) given that $a_{w}$ decrement leads to a decrease of the speed of both germination and mycelium growth until a minimum where neither germination nor growth occurs. Beside $a_{\mathrm{w}}$, temperature is recognized to limit mold growth on its own or in combination with $a_{\mathrm{w}}$ (Abellana et al., 1999; Marín et al., 1996). On the other hand, the role of $\mathrm{pH}$ in mold growth limitation has never been clearly established, at least in the range of mostly

* Corresponding author at: INRA, UMR1014 Secalim, Oniris, rue de la Géraudière, CS8225-44322 Nantes Cedex 3, France. Tel.: + 332517855 21; fax: + 33251785520 .

E-mail address: jeanne-marie.membre@oniris-nantes.fr (J.-M. Membré). bakery product formulation, i.e. range of $\mathrm{pH}$ 3.5-7.5 (Sautour et al., 2001b; Wheeler et al., 1991).

To assess quantitatively the effect of preservative factors on mold growth, the use of predictive microbiology models is valuable. In the recent past, various types of primary models have been developed to describe either germination or mycelium growth kinetics under various conditions (Dagnas and Membré, 2013; Dantigny et al., 2005a). In addition, several types of secondary models describing the effect of the preservative factors $a_{\mathrm{w}}$, temperature and $\mathrm{pH}$ on these kinetics have been suggested (Garcia et al., 2009). Among them, the Gamma-type models have been widely applied to mycelium radial growth rate, on various mold species (e.g., Aspergillus flavus, Aspergillus candidus, Aspergillus ochraceus, Aspergillus parasiticus, Aspergillus carbonarius, Penicillium expansum, Penicillium glabrum, Botrytis cinerea and Monascus ruber) and various food products (e.g., corn, grape, peanut, aromatized water and table olives) (Astoreca et al., 2012; Garcia et al., 2011; Huchet et al., 2013; Judet-Correia et al., 2010; Nevarez et al., 2009; Panagou et al., 2003; Tassou et al., 2007). Concerning the lag time for growth only few applications of the Gamma-type model structure have been described (Gougouli et al., 2011; Gougouli and Koutsoumanis, 2010; Huchet et al., 2013; Marín et al., 2009). This time includes the germination time and is driven by the effect of environmental factors (Gougouli and Koutsoumanis, 2012, 2013). When it has been modeled, this lag time was described as a function of only one preservative factor, either 
the $a_{\mathrm{w}}$ (Marín et al., 2009) or the temperature (Gougouli et al., 2011; Gougouli and Koutsoumanis, 2010).

The first objective of this study was to develop predictive microbiology models to assess the effect of $a_{\mathrm{w}}$, temperature, and, if necessary, $\mathrm{pH}$ on growth (lag time for growth and radial growth rate) of three molds isolated from spoiled bakery products. Once the models are developed and validated, they will enable to calculate the probability of having mold growth up to a visible mycelium before the time of consumption, and subsequently to determine the bakery product shelf-life (Dagnas and Membré, 2013). The models were developed for Aspergillus niger, Penicillium corylophilum and Eurotium repens, mold species frequently encountered in bakery products.

The second objective of this study was to assess whether the same model structure (i.e. same equation) could be applied to the three mold species studied here, meaning that the three species would have the same response to the hurdle factor combination, differing only by the response intensity or the range of parameter values (i.e. different model parameter estimates). If this assumption is right, that may simplify the future research in the field of mold spoilage in food as a general model framework will be in place.

The third objective of this study was to compare the secondary model outputs (equation structure and model parameter estimates) for both radial growth rate and lag time for growth. Indeed the aim was to assess if the duration of the lag time could be related to the radial growth rate in terms of water activity effect, temperature effect or $\mathrm{pH}$ effect (e.g., same cardinal values, proportionality between both kinetic parameters). If a relationship is found, future development in the predictive mycology area will be simplified: it will be possible to deduce the lag time from the mycelium radial growth rate, or vice versa.

\section{Materials and methods}

\subsection{Fungal strains}

One strain of three major fungal species responsible for the spoilage of bakery products was isolated, identified using phenotypic and genotypic methods and provided by the Culture Collection of Universite de Bretagne Occidentale (UBOCC, Plouzané, France). The strains were Eurotium repens UBOCC-A-112075, Aspergillus niger UBOCC-A-112064 and Penicillium corylophilum UBOCC-A-112081. They were maintained and subcultured bimonthly on Malt Extract Agar (MEA, AES Chemunex, Bruz, France).

\subsection{Spore suspension preparation}

The three strains were grown separately on MEA media for 7 days at $25{ }^{\circ} \mathrm{C}$ to obtain heavily sporulating cultures. Spores suspensions were then prepared by washing the cultures with sterile distillated water containing 0.01\% (vol/vol) Tween ${ }^{\circledR} 80$ (Merck KGaA, Darmstadt, Germany) (Dantigny et al., 2006). The spore concentration of each suspension was assessed using a Malassez counting chamber and adjusted if necessary to $10^{6}$ spores $/ \mathrm{mL}$ with appropriate dilutions. To minimize the potential impact of the water activity change between the suspension and the growth medium (as suggested by Nanguy et al. (2010)), the final suspensions were used as quickly as possible (less than a few minutes) for inoculation.

\subsection{Experimental design}

A 5-level Latin Square design was set up to study the effect of water activity $\left(a_{\mathrm{w}}\right)$, temperature $(\mathrm{T})$ and $\mathrm{pH}$ on mold growth within 25 combinations of experimental conditions per strain studied. This design allows reducing the number of experiments while keeping an acceptable level of accuracy and reliability in estimating the parameters (Mertens et al., 2012; Van Derlinden et al., 2013). The $a_{\mathrm{w}}$ was set at 0.80, 0.85, 0.90, 0.94 and 0.98 , the temperature at $15,21,25,30$ and $35^{\circ} \mathrm{C}$ and $\mathrm{pH}$ at 3 ,
$4,5,6$ and 7. The Latin Square design was carried out after a randomization of the factor level order. Three plates were used per combination ( $=75$ experiments) for each of the three strains studied ( $=225$ experiments). The experimental design was carried out twice (one repetition), which means a set of 450 experiments. Moreover, 22 mold growth experiments were found contaminated by unexpected molds and then discarded. Consequently, the final set of data contained 428 experimental mold growth curves. The three plates used for each experimental combination of one repetition corresponded to the repeatability of the experimental set up, the duplicates (the whole experimental design repeated once) to the reproducibility.

\subsection{Media preparation, inoculation and incubation}

All experiments were performed on MEA Petri dishes. Water activity values were adjusted by replacing a part of the water by glycerol during media preparation as recommended by Hocking and Pitt (1980). To determine the amount of glycerol added, a standard curve describing the water activity of the MEA medium as function of the glycerol part (in $\%$, wt/wt) was built (linear relationship, $R^{2}=0.998$, data not shown). Water activity measurements were performed with an $a_{\mathrm{w}}$ meter (LabMASTER- $\mathrm{a}_{\mathrm{w}}$, Novasina AG, Lachen, Switzerland). During media preparation $\mathrm{pH}$ values were adjusted by adding drops of either a $0.5 \mathrm{M} \mathrm{HCl}$ solution or a $0.5 \mathrm{M} \mathrm{NaOH}$ solution until the required value was reached. The $\mathrm{pH}$ was measured continuously for this operation with a $\mathrm{pH}$ meter (MP225, Mettler-Toledo GmbH, Schwerzenbach, Switzerland) equipped with a glass electrode. For pH 5, 6 and 7 adjustments were carried out before sterilization (the $\mathrm{pH}$ value was verified after the sterilization). For pH 3 and 4, adjustments were made after sterilization in a medium cooled down to $45^{\circ} \mathrm{C}$ to enable its further solidification. After sterilization process $\left(121^{\circ} \mathrm{C}\right.$ during $15 \mathrm{~min}$ ) adjusted MEA were poured $(20 \mathrm{~mL})$ into identified $90 \mathrm{~mm}$ diameter sterile Petri dishes. For each strain, $2 \times 10^{3}$ spores ( $2 \mu \mathrm{L}$ of the $10^{6}$ spores/mL suspension) were inoculated centrally.

All the inoculated dishes were then sealed with Parafilm ${ }^{\circledR}$ to avoid dehydration and incubated at the required temperatures in low temperature programmable incubators (MIR 154, Sanyo Electric Co., Ltd., Osaka, Japan). The Petri dishes at the same $a_{\mathrm{w}}$ and temperature were placed together with a mixture water/glycerol in sealed polyethylene bag to keep a better equilibrium.

\subsection{Growth measurement and primary modeling}

Each plate was checked daily for mold growth during 35 days (experimental duration chosen according to the shelf-life of the bakery products studied, i.e. 20-30 days). In case of growth, colony diameters were measured in two directions at right angles to each other with a digital caliper until the colony reached a limit value of $25 \mathrm{~mm}$. Indeed, after $25 \mathrm{~mm}$ it was noticed in some conditions, a radial growth rate slow-down, phenomenon also observed by Baranyi et al. (2014).

Radius of the colonies were then plotted against the time and fitted to a primary model with latency (Buchanan et al., 1997) (Eq. (1)) to estimate the lag time before mycelium growth (days) and the mycelium radial growth rate ( $\mathrm{mm} /$ day). The non-linear regression of the primary model was performed using the nls function from the R software (R-Development-Core-Team, 2012). The results were analyzed furthermore using the nlstools package (Baty and DelignetteMuller, 2012) implemented in R.

$R_{(t)}= \begin{cases}R_{0}, & t \leq \lambda \\ R_{0}+\mu \cdot(t-\lambda), & t>\lambda\end{cases}$

In Eq. (1), $t$ is the time (day), $R_{(t)}(\mathrm{mm})$ is the colony radius at time $t, R_{0}(\mathrm{~mm})$ is the initial colony radius (equal to the radius of the spore suspension inoculation drop, $3 \mathrm{~mm}$ ), $\lambda$ is the lag time before mycelium growth (days), and $\mu$ is the mycelium radial growth rate ( $\mathrm{mm}$ radius/day). 
When no growth was observed within 35 days (139 growth curves of 428 ), the lag time was defined as longer than 35 days $(\lambda>35$ days) and the radial growth rate as zero $(\mu=0)$. When the mycelium growth was too fast (12 growth curves of 428), there was not enough data to determine accurately the growth kinetics. In such a case, the growth rate was defined as higher than the highest growth rate calculated for the same mold strain, $\mu_{\max }$. Likewise, the lag time was defined as lower than the lowest lag time calculated for the same mold strain, $\lambda_{\min }$. These data were analyzed as left or right censored data: left for $1 / \lambda<1 / 35$ days, right for $1 / \lambda>1 / \lambda_{\min }$ and for $\mu>\mu_{\max }$.

\subsection{Secondary modeling}

The 428 estimated $\mu$ and $\lambda$ parameters were then expressed as function of $a_{\mathrm{w}}$ and temperature using Gamma-concept models firstly introduced by Zwietering et al. (1993). The radial growth rate, $\mu$, was modeled after a square root transformation (Eq. (2)), and the inverse of the lag time, $1 / \lambda$, was modeled also after a square root transformation (Eq. (3)) allowing the stabilization of the variance as recommended by Dantigny and Bensoussan (2008).

$\sqrt{\mu_{K}}=\sqrt{\mu_{K}^{\mathrm{opt}}} \cdot \sqrt{\left(\gamma_{K}^{\mu}\left(a_{\mathrm{w}}\right) \cdot \gamma_{K}^{\mu}(T)\right)}+\varepsilon_{\mu}$

$\sqrt{1 /{ }_{\lambda_{K}}}=\sqrt{1 /{ }_{\lambda_{K}^{\text {opt }}}} \cdot \sqrt{\left(\gamma_{K}^{\lambda}\left(a_{\mathrm{w}}\right) \cdot \gamma_{K}^{\lambda}(T)\right)}+\varepsilon_{\lambda}$

where $K$ represents the strains ( $K=1,2$ and 3 for E. repens, $A$. niger and $P$. corylophilum respectively), and $\mu^{\mathrm{opt}}$ and $\lambda^{\mathrm{opt}}$ are the values of $\mu$ and $\lambda$ at optimal $a_{\mathrm{w}}$ and temperature (T). The $\gamma($.) terms represent the effect of $a_{\mathrm{w}}$ and temperature on $\mu$ and $\lambda$.

The two models had a hierarchical structure: the terms $\varepsilon_{\mu}$ and $\varepsilon_{\lambda}$ representing the residual errors were assumed to be identical whatever the species. On the other hand, the residual errors were not further broken down into repeatability and reproducibility error terms.

For each strain and for both kinetic responses (radial growth rate and lag time for growth), several cardinal model structures were tested and their parameters estimated through Bayesian inference. The final estimated parameters were $T_{\min }, T_{\mathrm{opt}}, T_{\mathrm{max}}, a_{\mathrm{w} \text { min }}, a_{\mathrm{w} \text { opt }}, \sqrt{ } \mu^{\mathrm{opt}}$ and $\sqrt{ } 1 / \lambda^{\text {opt }}$. The parameter $a_{\mathrm{w} \text { max }}$ was fixed to the value 1 as suggested by Sautour et al. (2001a) since the three mold species studied have been reported to grow at $a_{\mathrm{w}}$ higher than 0.99 (Andrews and Pitt, 1987; Belli et al., 2004; Pitt and Hocking, 2009).

\subsection{Bayesian inference}

In Bayesian inference, the posterior probabilities are defined as proportional to prior probabilities times the likelihood of the data (Eq. (4)).

$p($ parameters $/$ data $) \propto P($ parameters $) \times P($ data $/$ parameters $)$

In other words Bayesian inference enables to integrate an a priori knowledge on the model parameters through prior probability distributions into the estimation process. Here, Bayesian inference was used to include information on $A$. niger $T_{\mathrm{opt}}$ and $T_{\mathrm{max}}$, for which information was available (Cuppers et al., 1997; Gougouli et al., 2011; Gougouli and Koutsoumanis, 2010, 2012; Parra and Magan, 2004). The prior distributions for the three species parameters were chosen as normal distributions (Table 1). Normal distributions for the model parameters are often chosen in Bayesian statistics. The reason for this choice lies in the following statistical property: with a Normal likelihood and a normal prior, the posterior distribution is also a normal distribution (Marin and Robert, 2007). This property is an algebraic convenience; otherwise a difficult numerical integration may be necessary during the model inferring step.
Table 1

Prior probability distributions of the parameters estimated through the Bayesian inference process for both radial growth rate and lag time models. The distributions are presented as $\sim N$ (mean; variance).

\begin{tabular}{llll}
\hline & Eurotium repens & Aspergillus niger & Penicillium corylophilum \\
\hline$a_{\mathrm{w} \min }$ & $\sim \mathcal{N}(0.8 ; 100)$ & $\sim \mathcal{N}(0.8 ; 100)$ & $\sim \mathcal{N}(0.8 ; 100)$ \\
$a_{\mathrm{w} \text { opt }}$ & $\sim \mathcal{N}(0.95 ; 100)$ & $\sim \mathcal{N}(0.95 ; 100)$ & $\sim \mathcal{N}(0.95 ; 100)$ \\
$a_{\mathrm{w} \max }$ & $1^{\mathrm{a}}$ & $1^{\mathrm{a}}$ & $1^{\mathrm{a}}$ \\
$T_{\min }$ & $\sim \mathcal{N}(5 ; 1000)$ & $\sim \mathcal{N}(5 ; 1000)$ & $\sim \mathcal{N}(5 ; 1000)$ \\
$T_{\mathrm{opt}}$ & $\sim \mathcal{N}(27 ; 1000)$ & $\sim \mathcal{N}(34 ; 2.341)$ & $\sim \mathcal{N}(27 ; 1000)$ \\
$T_{\max }$ & $\sim \mathcal{N}(40 ; 1000)$ & $\sim \mathcal{N}(45.5 ; 1.638)$ & $\sim \mathcal{N}(40 ; 1000)$ \\
$\sqrt{\mu_{K}^{\text {opt }}}$ & $\sim \mathcal{N}(3 ; 1000)$ & $\sim \mathcal{N}(3 ; 1000)$ & $\sim \mathcal{N}(3 ; 1000)$ \\
$\sqrt{1 / \lambda_{K}^{\text {opt }}}$ & $\sim \mathcal{N}(2 ; 1000)$ & $\sim \mathcal{N}(2 ; 1000)$ & $\sim \mathcal{N}(2 ; 1000)$ \\
$\varepsilon_{\mu}$ and $\varepsilon_{\lambda}$ & $\sim \mathcal{N}\left(0 ; \sigma^{2}\right)$ & $\sim \mathcal{N}\left(0 ; \sigma^{2}\right)$ & $\sim \mathcal{N}\left(0 ; \sigma^{2}\right)$ \\
& with & with & with \\
& $\sigma \sim \mathcal{U}(0.1 ; 10)$ & $\sigma \sim \mathcal{U}(0.1 ; 10)$ & $\sigma \sim \mathcal{U}(0.1 ; 10)$ \\
\hline
\end{tabular}

a Parameters not estimated but fixed.

Bayesian inference was also chosen as it facilitates the integration of censored data ( $139+12$ lag time data of $428 ; 12$ growth rate data of 428). Indeed, Eq. (4) was modified as follows (Mitra, 2013):

Right censored:

$P($ parameters $/$ data $) \propto P($ paramters $) \times \prod_{i \in U} \mathrm{f}\left(Y_{i}\right) \times \prod_{i \in C}\left\{1-\mathrm{F}\left(Y_{i}\right)\right\}$

Left censored:

$P($ parameters $/$ data $) \propto P($ parameters $) \times \prod_{i \in U} \mathrm{f}\left(Y_{i}\right) \times \prod_{i \in C} \mathrm{~F}\left(Y_{i}\right)$

Where $Y$ is the response studied ( $\sqrt{ } \mu$ or $\sqrt{ } 1 / \lambda), f(Y)$ is the probability distribution function of $Y, F(Y)$ is the cumulative distribution function and $U$ and $C$ denote the sets that contain the uncensored and censored data, respectively.

Computing these equations (from 4 to 6 ) is often analytically impossible. A variety of methods have been developed to carry out a modeling approach based on Bayesian inference. One of the most popular ones is the Markov Chain Monte Carlo technique in which a Markov Chain is used to sample for the posterior distributions (Dakins et al., 1996; Patwardhan and Small, 1992). The solving process, where the posterior distributions of the model parameters are computed at each iteration, was run with the WinBUGS package (Lunn et al., 2000). To check the convergence of the iteration process, visual analyses (history function and Gelman and Rubin diagnostic) of three independent chains were performed. Twenty thousand iterations were run; the first 10,000 iterations were eliminated (burn-in period). Moreover, the pairwise parameter correlations were calculated and their scatter plots were generated.

\subsection{Goodness of fit and choice of the Gamma terms}

For both radial growth rate and lag time models, several Gamma terms were tested: for temperature and $a_{\mathrm{w}}$, cardinal model equations with $n=1$ or $n=2$ (Rosso et al., 1995), also for $a_{\mathrm{w}}$ an equation adapted from Zwietering et al. (1996). The first criterion to decide if a Gamma term was potentially suitable was the convergence after 20,000 iterations. If there was no convergence, the Gamma term was discarded. Next, a visual inspection of the residual errors (i.e. observed data minus fitted data) was carried out. In case of bias, the Gamma term was discarded. Finally, both standard deviation of the model errors $\left(\sigma_{\mu}\right.$ and $\sigma_{\lambda}$ ) and the deviance information criteria $\left(\right.$ DIC $_{\mu}$ and DIC ${ }_{\lambda}$ ) were calculated and compared. The standard deviation of the model error also called the root mean square error shows the average discrepancy between observed data and their fitted values and is a measure of 
goodness-of-fit for regression models (Ratkowsky, 2004). The DIC is a model comparison criterion (generalization of the Akaike information criterion) that combines Bayesian measure of fit with a measure of model parsimony (Berg et al., 2004). The Gamma term leading to the smallest values of these two statistical criteria was kept in the model.

\subsection{Assessing the impact of $\mathrm{pH}$}

Initially, the pH effect on mold growth responses was assessed on the three molds with a pH Gamma term written as follows:

$$
\gamma_{K}^{\mu}(\mathrm{pH})=\left\{\begin{array}{cc}
0, & \mathrm{pH} \leq \mathrm{pH}_{\min } \\
\frac{\left(\mathrm{pH}-\mathrm{pH}_{\text {max }}\right)\left(\mathrm{pH}-\mathrm{pH}_{\text {min }}\right)}{\left[\left(\mathrm{pH}-\mathrm{pH}_{\max }\right)\left(\mathrm{pH}-\mathrm{pH}_{\text {min }}\right)\right]-\left(\mathrm{pH}-\mathrm{pH}_{\mathrm{opt}}\right)^{2},} & \mathrm{pH}_{\text {min }}<\mathrm{pH}<\mathrm{pH}_{\max } \\
0, & \mathrm{pH} \geq \mathrm{pH}_{\max }
\end{array}\right.
$$

$$
\text { In Eq. (7), } \mathrm{pH}_{\mathrm{opt}}=\frac{\mathrm{pH}_{\min }+\mathrm{pH}_{\max }}{2} \text {. }
$$

However, with this Gamma term applied to the three strains in the two hierarchical models (Eqs. (2) and (3)) and even after 50,000 iterations, convergence of the Markov chains did not occur. Consequently, to check if the $\mathrm{pH}$ had an effect on either lag time for growth or radial growth rate, the residual errors calculated from the model without the pH Gamma term (Eqs. (2) and (3)) were analyzed graphically. In case of trend (i.e. indicating a potential pH effect), the hierarchical models were split into single-strain models on which the $\mathrm{pH}$ Gamma term was tested as described above.

\section{Results}

\subsection{Primary modeling}

On 428 growth experiments (450 minus 22 contaminated), 139 led to no growth within 35 days ( $\mu$ set to zero and $\lambda$ set to $>35$ days) and 289 led to growth within 35 days. In the latter $\mu$ and $\lambda$ were estimated through primary modeling. The relative errors of the parameters, i.e. standard error divided by mean, were estimated to a mean of $3.3 \%$ ( median $=2.4 \%$ ) and $8.4 \%$ (median $=3.8 \%$ ) for $\mu$ and $\lambda$, respectively.

\subsection{Predictive models for radial growth rate and lag time}

Among the Gamma terms tested, the ones presented in Tables 2 and 3 (Eqs. (8) to (12)) gave the best results regarding the statistical criteria (smallest errors and DIC) and were kept in the models.

The standard deviations of the residual errors were estimated to 0.31 ( $23 \%$ of the average response) and 0.16 (26\% of the average response) for radial growth rate and lag time models, respectively. The parameters were accurately estimated (Tables 4 and 5 ) except the $T_{\min }$ for mycelium growth of E. repens and $P$. corylophilum, which showed a standard deviation higher than $3{ }^{\circ} \mathrm{C}$. No structural correlation was found between the estimated parameters (Figs. S1 and S2). The fitted and observed values of radial growth rates and lag times were plotted as a function of $a_{\mathrm{w}}$ (Figs. 1 and 2, respectively), for the three molds.

\subsection{Effect of $\mathrm{pH}$}

It was not possible to run the Markov Chain when a pH Gamma term was included in the hierarchical models neither for the growth rate nor for the lag time for growth. Then, to check if the $\mathrm{pH}$ might have an effect on one of these two responses, a further investigation was done. The residual errors of both models without pH Gamma terms (Eqs. (2) and (3)) were plotted versus the $\mathrm{pH}$ for each of the strain. While there was no bias for the lag time of any of the strain (data not shown), a slight structure of the residual error plot was noticed for E. repens growth rate model (Fig. 3A). To assess whether this effect was significant, a comparison between a growth rate model (Eq. (2)) limited to E. repens, completed with the pH Gamma term as described in Eq. (7) and a growth rate model (Eq. (2)) limited to E. repens without pH Gamma term was made. Results indicated a slight effect of $\mathrm{pH}$ on E. repens radial growth rate $\left(\sigma_{\mu}=0.36\right.$ and 0.42 for the model with $\mathrm{pH}$ and the model without $\mathrm{pH}$ term, respectively; DIC $=126$ and 169 for the model with $\mathrm{pH}$ and the model without $\mathrm{pH}$ term, respectively). The parameter values associated with E. repens growth rate model (Eq. (2)) completed by the $\mathrm{pH}$ Gamma term (Eq. (7)) are provided in Table 6, the residual error plot is given in Fig. 3B.

\subsection{Effect of temperature and $a_{w}$ on the mycelium radial growth rate}

The model structure describing the effect of $a_{\mathrm{w}}$ on $E$. repens radial growth rate (cardinal model, $n=2$, Eq. (8) in Table 2) differed from the one applied to $A$. niger and $P$. corylophilum (equation adapted from Zwietering et al. (1996), Eq. (9) in Table 2) (Fig. 1). Regarding the storage temperature, the three molds showed a comparable pattern of mycelium growth described by a $n=2$ cardinal model (Eq. (10) in Table 2). In terms of range of parameter values, although the $a_{\mathrm{w}}$ min of the three strains were similar (ca. 0.79), E. repens had an $a_{\mathrm{w} \text { opt value }}$ of 0.91 , whereas A. niger and P. corylophilum showed the highest growth rates at the maximum $a_{\mathrm{w}}$ tested (i.e. 0.98). A. niger was able to grow at higher temperature than $E$. repens and P. corylophilum (Table 4). These two latter strains grew at temperature between 0 and $35{ }^{\circ} \mathrm{C}$ with an optimum temperature value estimated to $29.0{ }^{\circ} \mathrm{C}$ for E. repens and to $25.8^{\circ} \mathrm{C}$ for $P$. corylophilum. On the other hand, $A$. niger had a $T_{\min }$, $T_{\text {opt }}$ and $T_{\max }$ for mycelium growth of $7.0^{\circ} \mathrm{C}, 34.9{ }^{\circ} \mathrm{C}$ and $45.7^{\circ} \mathrm{C}$, respectively.

Table 2

Gamma terms associated with the radial growth rate model (Eq. (2)).

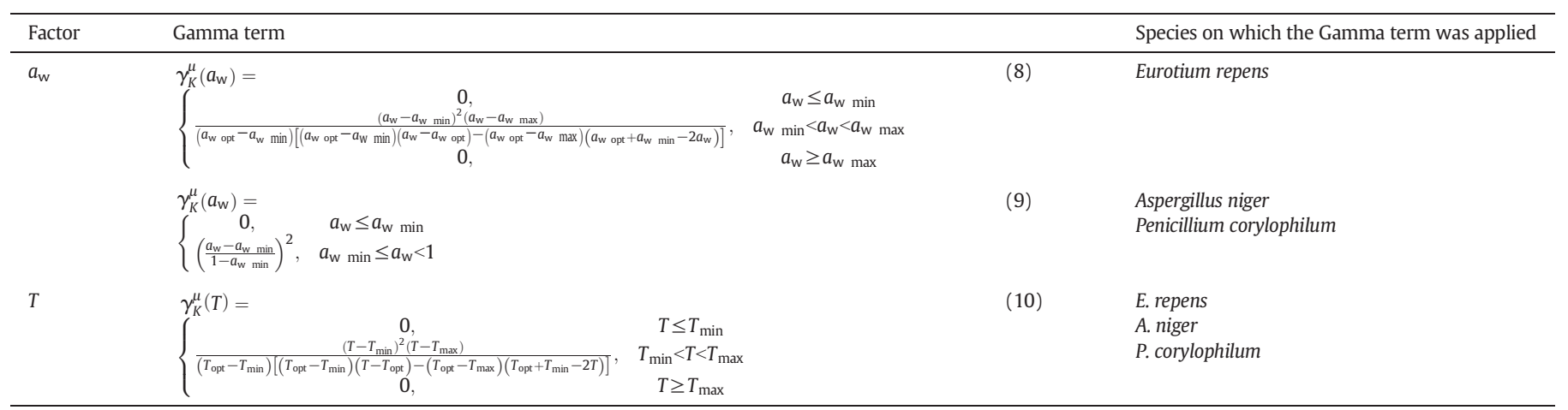


Table 3

Gamma terms associated with the lag time for growth model (Eq. (3)).

\begin{tabular}{|c|c|c|c|}
\hline Factor & Gamma term & & Species on which the Gamma term was applied \\
\hline$a_{\mathrm{w}}$ & 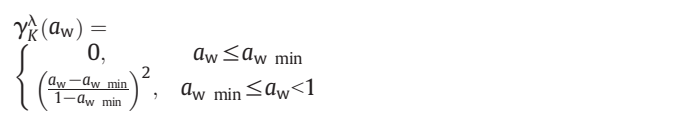 & $(11)$ & $\begin{array}{l}\text { Eurotium repens } \\
\text { Aspergillus niger } \\
\text { Penicillium corylophilum }\end{array}$ \\
\hline$T$ & $\begin{array}{l}\gamma_{K}^{\lambda}(T)= \\
\left\{\begin{array}{cc}0, & T \leq T_{\min } \\
\frac{\left(T-T_{\min }\right)^{2}\left(T-T_{\max }\right)}{\left(T_{\mathrm{opt}}-T_{\min }\right)\left[\left(T_{\mathrm{opt}}-T_{\min }\right)\left(T-T_{\mathrm{opt}}\right)-\left(T_{\mathrm{opt}}-T_{\max }\right)\left(T_{\mathrm{opt}}+T_{\min }-2 T\right)\right]}, & T_{\min }<T<T_{\max } \\
0, & T \geq T_{\max }\end{array}\right.\end{array}$ & $(12)$ & $\begin{array}{l}\text { E. repens } \\
\text { A. niger } \\
\text { P. corylophilum }\end{array}$ \\
\hline
\end{tabular}

\subsection{Effect of temperature and $a_{w}$ on the lag time for growth}

The same model structure was applied to E. repens, A. niger and $P$. corylophilum lag times, for describing in one hand the $a_{\mathrm{w}}$ effect (Eq. (11) in Table 3), and on the other hand the temperature effect (Eq. (12) in Table 3). Lag times for mycelium growth were relatively short (0.5-3 days) near to $a_{\mathrm{w}}$ of 0.98 and increased with the decrease of $a_{\mathrm{w}}$ until the $a_{\mathrm{w} \text { min }}$ values were reached (Fig. 2). E. repens had the lowest $a_{\mathrm{w}}$ min with a value of 0.76 (Table 5 ). A. niger and P. corylophilum were comparable with an $a_{\mathrm{w}}$ min around 0.80 . E. repens had the narrowest range of temperature for the lag time with $T_{\min }, T_{\mathrm{opt}}$ and $T_{\max }$ estimated to $12.8,25.4$ and $35.3^{\circ} \mathrm{C}$, respectively. P. corylophilum showed similar cardinal temperature values even if the range was slightly greater $\left(T_{\min }\right.$ and $T_{\max }$ estimated to 9.8 and $37.0{ }^{\circ} \mathrm{C}$, respectively). A. niger showed the largest range of cardinal temperature values with 9.0, 37.4 and $44.5{ }^{\circ} \mathrm{C}$ as minimum, optimum and maximum, respectively.

\subsection{Comparison between radial growth rate and lag time for growth}

For $E$. repens, the $a_{\mathrm{w}}$ Gamma terms were different for growth rate and lag time, meaning that overall, these both growth responses were not correlated. These findings were confirmed by observing the raw data (Fig. 4A).

On the other hand the same model structure was applied for both growth responses of $A$. niger and $P$. corylophilum. Consequently, a deeper analysis of the cardinal model parameter values was necessary to conclude whether a proportional relationship between growth rate and lag time exists. For A. niger, the cardinal parameter values (related to $a_{\mathrm{w}}$ and temperature) for lag time and for radial growth rate were equivalent (Tables 4 and 5), while they were somewhat different for $P$. corylophilum. Indeed, for $P$. corylophilum $T_{\min }$ was estimated to 0.9 and $9.8^{\circ} \mathrm{C}$ for radial growth rate model and lag time for growth model, respectively. However, this difference has to be interpreted with care as the parameter standard deviations are large (from 2 to $5{ }^{\circ} \mathrm{C}$ ). In addition to comparing the model parameters, the observation of the raw data indicated a slight proportional relationship between $\sqrt{ } \mu$ and $\sqrt{ } 1 / \lambda$ (Fig. $4 \mathrm{~B}$ and $C$ ), the product $\mu$ times $\lambda$ being 6.7 with a standard deviation of 3.7 for A. niger and 3.3 (standard deviation 1.6) for P. corylophilum.

\section{Discussion}

Original data on E. repens, A. niger and $P$. corylophilum growth have been collected. The experimental period of 35 days was set accordingly to the shelf-life of the bakery products studied (20-30 days). Then, predictive models have been developed for two responses (lag time for mycelium growth and mycelium radial growth rate), two factors ( $a_{\mathrm{w}}$ and temperature) and three mold species with satisfactory results: small residual errors, parameters estimated accurately and no correlation between parameters. Moreover, the parameter values were compared with those reported in the literature (Table 7). For A. niger, the results were in agreement for both temperature and water activity parameter values. For $P$. corylophilum there was not enough data to reach a definitive conclusion. Concerning E. repens, temperature parameter estimates obtained in our study matched those reported in the literature. The difference found for $a_{\mathrm{w} \text { min }}$ may be explained by the different food matrices from which the strains were isolated. For example, in our study the strain was isolated from bakery product $\left(a_{\mathrm{w}} 0.85\right)$ while in Andrews and Pitt (1987) the strain studied came from dried fish ( $\left.a_{\mathrm{w}} 0.65-0.79\right)$.

The advantages of having predictive models based on a Gamma model structure have been already largely mentioned in the literature and are (i) parsimony and interpretability of the model parameters, and (ii) possibility to complete the model by adding the effect of an extra preservative factor without breaking down the existing model structure. The Gamma type models have already been applied

Table 4

Estimated parameters of the radial growth rate model (Eq. (2)).

\begin{tabular}{|c|c|c|c|c|c|c|}
\hline & & & Mean & sd & Lower 95\% CI & Upper 95\% CI \\
\hline \multirow[t]{9}{*}{ Temperature $\left({ }^{\circ} \mathrm{C}\right)$} & \multirow[t]{3}{*}{$T_{\min }$} & Eurotium repens & 0.6 & 3.2 & -6.5 & 6.0 \\
\hline & & Aspergillus niger & 7.0 & 1.5 & 3.8 & 9.6 \\
\hline & & Penicillium corylophilum & 0.9 & 5.0 & -9.6 & 10.1 \\
\hline & \multirow[t]{3}{*}{$T_{\mathrm{opt}}$} & E. repens & 29.0 & 1.1 & 28.9 & 31.6 \\
\hline & & A. niger & 34.9 & 1.0 & 33.0 & 37.1 \\
\hline & & P. corylophilum & 25.8 & 1.4 & 23.3 & 28.5 \\
\hline & \multirow[t]{3}{*}{$T_{\max }$} & E. repens & 35.1 & 0.1 & 35.0 & 35.3 \\
\hline & & A. niger & 45.7 & 1.2 & 43.2 & 48.1 \\
\hline & & P. corylophilum & 35.8 & 0.4 & 35.3 & 36.7 \\
\hline \multirow[t]{4}{*}{ Water activity } & \multirow[t]{3}{*}{$a_{\mathrm{w} \min }$} & E. repens & 0.789 & $3.13 \times 10^{-3}$ & 0.783 & 0.795 \\
\hline & & A. niger & 0.795 & $3.49 \times 10^{-3}$ & 0.788 & 0.802 \\
\hline & & P. corylophilum & 0.802 & $7.43 \times 10^{-3}$ & 0.788 & 0.817 \\
\hline & $a_{\mathrm{w} \mathrm{opt}}$ & E. repens & 0.914 & $3.41 \times 10^{-3}$ & 0.908 & 0.921 \\
\hline \multirow[t]{3}{*}{$\sqrt{ } \mu^{\mathrm{opt}}(\mathrm{mm} / \mathrm{day})^{0.5}$} & & E. repens & 2.03 & 0.06 & 1.92 & 2.17 \\
\hline & & A. niger & 3.71 & 0.13 & 3.47 & 3.98 \\
\hline & & P. corylophilum & 1.95 & 0.08 & 1.80 & 2.10 \\
\hline$\sigma_{\mu}$ & & & 0.31 & 0.01 & 0.29 & 0.33 \\
\hline
\end{tabular}


Table 5

Estimated parameters of the lag time for growth model (Eq. (3)).

\begin{tabular}{|c|c|c|c|c|c|c|}
\hline & & & Mean & sd & Lower 95\% CI & Upper 95\% CI \\
\hline \multirow[t]{9}{*}{ Temperature $\left({ }^{\circ} \mathrm{C}\right)$} & \multirow[t]{3}{*}{$T_{\min }$} & Eurotium repens & 12.8 & 1.0 & 10.6 & 14.3 \\
\hline & & Aspergillus niger & 9.0 & 0.9 & 7.1 & 10.7 \\
\hline & & Penicillium corylophilum & 9.8 & 2.2 & 4.8 & 13.3 \\
\hline & \multirow[t]{3}{*}{$T_{\text {opt }}$} & E. repens & 25.4 & 0.5 & 24.6 & 26.6 \\
\hline & & A. niger & 37.4 & 1.0 & 35.6 & 39.5 \\
\hline & & P. corylophilum & 25.7 & 0.7 & 24.7 & 27.2 \\
\hline & \multirow[t]{3}{*}{$T_{\max }$} & E. repens & 35.3 & 0.1 & 35.1 & 35.7 \\
\hline & & A. niger & 44.5 & 1.3 & 41.9 & 47.0 \\
\hline & & P. corylophilum & 37.0 & 0.5 & 36.2 & 38.1 \\
\hline \multirow[t]{3}{*}{ Water activity } & \multirow[t]{3}{*}{$a_{\mathrm{w} \min }$} & E. repens & 0.763 & $9.45 \times 10^{-3}$ & 0.743 & 0.780 \\
\hline & & A. niger & 0.801 & $3.71 \times 10^{-3}$ & 0.793 & 0.809 \\
\hline & & P. corylophilum & 0.811 & $6.15 \times 10^{-3}$ & 0.799 & 0.823 \\
\hline \multirow[t]{3}{*}{$\sqrt{ } 1 / \lambda^{\text {opt }}(1 / \text { day })^{0.5}$} & & E. repens & 1.05 & 0.04 & 0.98 & 1.12 \\
\hline & & A. niger & 2.00 & 0.10 & 1.83 & 2.20 \\
\hline & & P. corylophilum & 1.26 & 0.04 & 1.18 & 1.34 \\
\hline$\sigma_{\lambda}$ & & & 0.16 & 0.01 & 0.14 & 0.17 \\
\hline
\end{tabular}

Eurotium repens

Aspergillus niger

Penicillium corylophilum

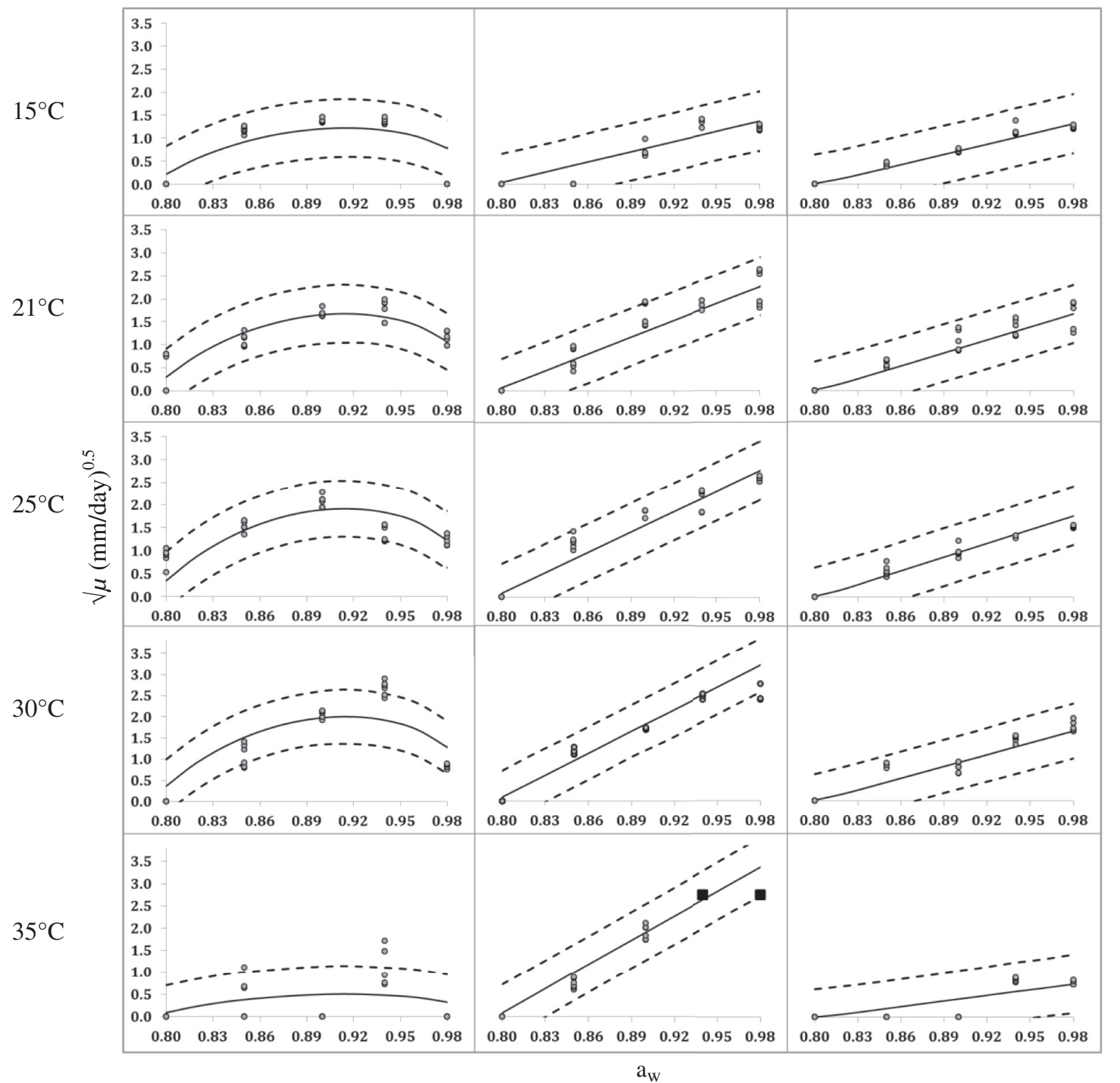

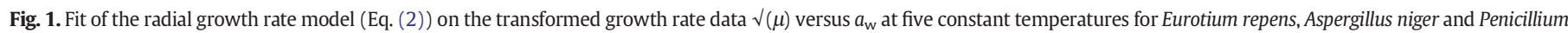
corylophilum. Observed growth rate data (O) and right censored data ( $\mathbf{(})$; model (solid lines) and 95\% credibility interval (dashed lines). 
Eurotium repens

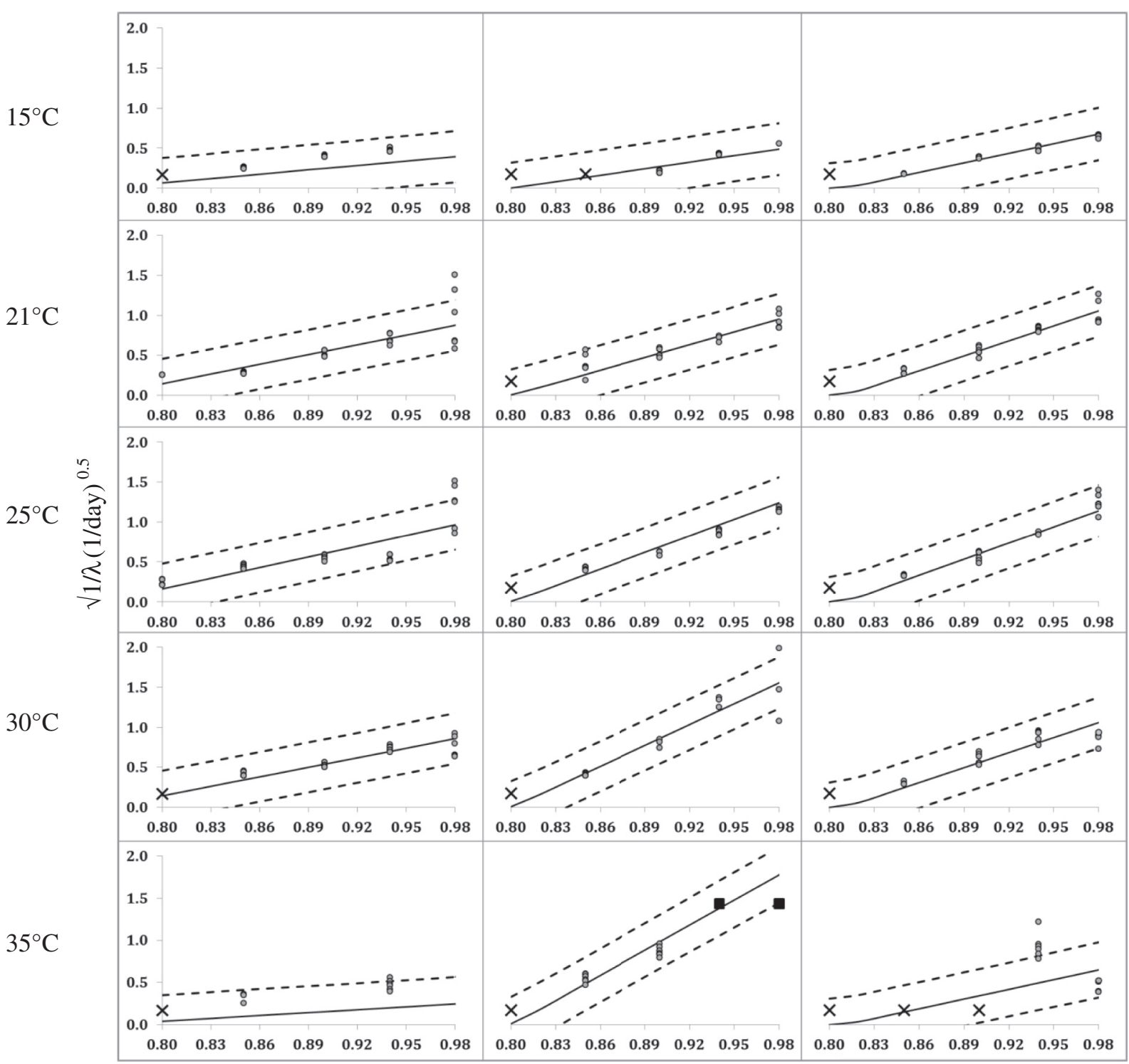

$\mathrm{a}_{\mathrm{W}}$

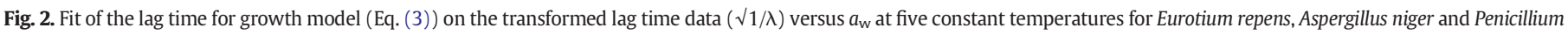
corylophilum. Observed lag time data $(O)$, right censored data ( $)$ and left censored data (x); model (solid lines) and $95 \%$ credibility interval (dashed lines).

A

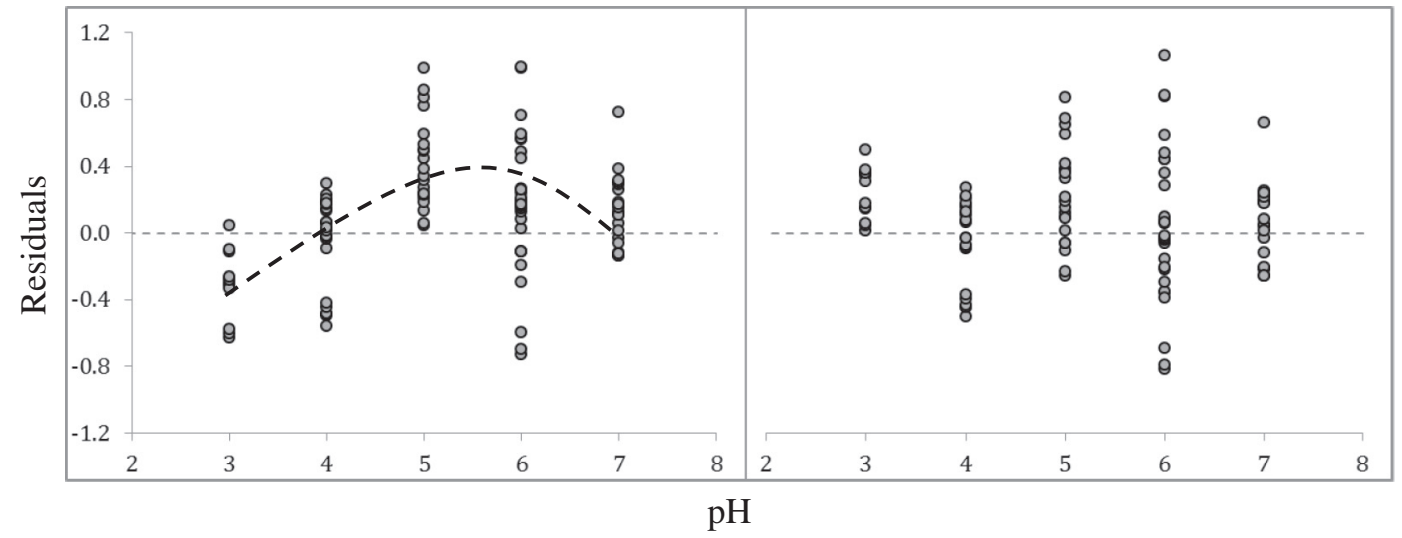

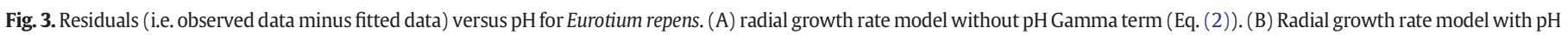
Gamma term (Eq. (2) completed with Eq. (7)). The black dashed line emphasizes a potential pH effect. 
Table 6

Estimated parameters of the radial growth rate model (Eq. (2)) completed with the pH Gamma term (Eq. (7)) applied to Eurotium repens.

\begin{tabular}{llcllc}
\hline & & Mean & sd & Lower 95\% CI & Upper 95\% CI \\
\hline \multirow{2}{*}{ Temperature $\left({ }^{\circ} \mathrm{C}\right)$} & $T_{\min }$ & 3.5 & 3.5 & -4.4 & 9.4 \\
& $T_{\mathrm{opt}}$ & 27.2 & 1.1 & 25.2 & 29.4 \\
\multirow{4}{*}{ Water activity } & $T_{\max }$ & 35.3 & 0.1 & 35.1 & 35.6 \\
& $a_{\mathrm{w} \text { min }}$ & 0.786 & $4.33 \times 10^{-3}$ & 0.786 & 0.793 \\
$\mathrm{pH}$ & $a_{\mathrm{w} \text { opt }}$ & 0.917 & $4.16 \times 10^{-3}$ & 0.909 & 0.925 \\
& $\mathrm{pH}_{\min }$ & 2.5 & 0.2 & 2.5 & 2.7 \\
& $\mathrm{pH}_{\mathrm{opt}}$ & 5.6 & 0.2 & 5.6 & 6.2 \\
$\sqrt{ } \mu^{\text {opt }}(\mathrm{mm} / \text { day })^{0.5}$ & $\mathrm{pH}_{\max }$ & 8.8 & 0.6 & 8.1 & 10.3 \\
$\sigma_{\mu}$ & & 2.30 & 0.08 & 2.14 & 2.45 \\
\hline
\end{tabular}

successfully to fungi, for example in Deschuyffeleer et al. (2013), Gougouli et al. (2011) and Rosso and Robinson (2001).

The originality of the study relies on developing Gamma models (i) for both radial growth rate and lag time for growth, and (ii) for three different mold species representative of bakery spoilage. With both radial growth rate and lag time, it is now possible to calculate the consumer rejection time, defined as the sum of the lag time for growth and the time to reach a visible limit when the mycelium growth starts (Horner and Anagnostopoulos, 1973), for any $a_{\mathrm{w}}$ and temperature combination (Eq. (13)). This model development step is a prerequisite toward shelf-life prediction (Dagnas and Membré, 2013; Gougouli et al., 2011).

$t_{K}^{\mathrm{v}}=\lambda_{K}+\frac{D_{\mathrm{v}}}{\mu_{K}}$

In Eq. (13) $K, \mu$ and $\lambda$ are the same as in Eqs. (2) and (3), $t_{\mathrm{v}}$ is the time to visible growth (also known as the rejection time) and $D_{\mathrm{v}}$ is the visible diameter and generally set to $3 \mathrm{~mm}$ (Gougouli et al., 2011).

Moreover, having predictive models developed for three mold species involved in the spoilage of a given food product enables to have a robust assessment of the microbial shelf-life.

In addition, the development of predictive models for three different mold species offers the opportunity to compare the mold behavior through their model structure. Our results showed that the same model framework (i.e. one model structure whatever the mold species, regarding water activity, temperature and $\mathrm{pH}$ ) to assess growth was not applicable.

Firstly, it was demonstrated that mycelium of E. repens grows faster at low $a_{\mathrm{w}}$ values (c.a. 0.91 ), while optimum mycelium growth of $A$. niger and $P$. corylophilum occurs at high $a_{\mathrm{w}}(>0.98)$. These two different behaviors led to two different model structures. Secondly, E. repens was affected by $\mathrm{pH}$, in the range $3-8$, whereas $A$. niger and $P$. corylophilum were not. This finding differs from what is generally reported in the literature, i.e. the factor $\mathrm{pH}$ is often considered as having no effect on mold growth within the range 3-8 (Sautour et al., 2001b; Wheeler et al., 1991).

On the other hand, for the temperature effect, the same Gamma term structure (Eqs. (10) and (12)) was applied on the three species, to predict both growth rate and lag time. Likewise, same Gamma terms for $a_{\mathrm{w}}$ and temperature were successfully applied to the three species lag time. Although this result is promising, it has to be interpreted with care. For instance, Gock et al. (2003) have shown that Xeromyces bisporus germinated faster (i.e. shorter lag time) at very low $a_{\mathrm{w}}$ (i.e. from 0.86 to 0.89 ) than at $a_{\mathrm{w}}$ close to 1 . In such a case, modeling the effect of $a_{\mathrm{w}}$ on the lag time of $X$. bisporus should lead to a different model structure from what has been developed in this study, for example a cardinal model with $n=2$ (same structure as Eq. (8)) instead of Eq. (11), might be appropriate. Overall, it seems reasonable to conclude that the behavior of the mold species varies sufficiently for not being described by a unique growth model structure. Consequently, for future research with other mold species, it will be necessary to verify which model structure has to be selected, that is a process which might be time and effort consuming. Nevertheless, our study confirmed that the Gamma model (within a short selection of Gamma terms) described satisfactorily the mold growth behavior as a function of the environmental factors.

Gougouli and Koutsoumanis (2010) were among the first authors that studied the relationship between $\mu$ and $\lambda$ of filamentous fungi. In their study, the product $\mu$ times $\lambda$ was found relatively constant for A. niger and Penicillium expansum at different storage temperatures and then the authors concluded that a proportional relationship between lag time and growth rate may be verified for mold growth. In their study on Aspergillus candidus, Huchet et al. (2013) have quantified the effect of temperature and $a_{\mathrm{w}}$ on the radial growth rate, and assuming $\mu$ times $\lambda$ constant, calculated the lag time for growth before concluding on shelf-life recommendations. In our study, whereas a pattern was noticed between $\sqrt{ } \mu$ and $\sqrt{ } 1 / \lambda$, the product $\mu$ times $\lambda$ was not constant enough to conclude to proportionality between these two growth responses for $A$. niger and $P$. corylophilum. Moreover, for E. repens the product $\mu$ times $\lambda$ was not constant, and the impacts of $a_{\mathrm{w}}$ on lag time and mycelium growth were significantly different and consequently modeled differently. Overall, the lag time for growth and mycelium growth process correspond to two different, although subsequent, biological phenomena. The lag time studied here encompasses lag time before germination (spore activation), spore swelling, polarized growth (germ tube formation) and exponential hyphal elongation (d'Enfert, 1997; Gougouli and Koutsoumanis, 2013), while mycelium growth corresponds to hyphal division and mycelium elongation. In our opinion, the effect of environmental factors on lag time and mycelium growth rate should be modeled separately.

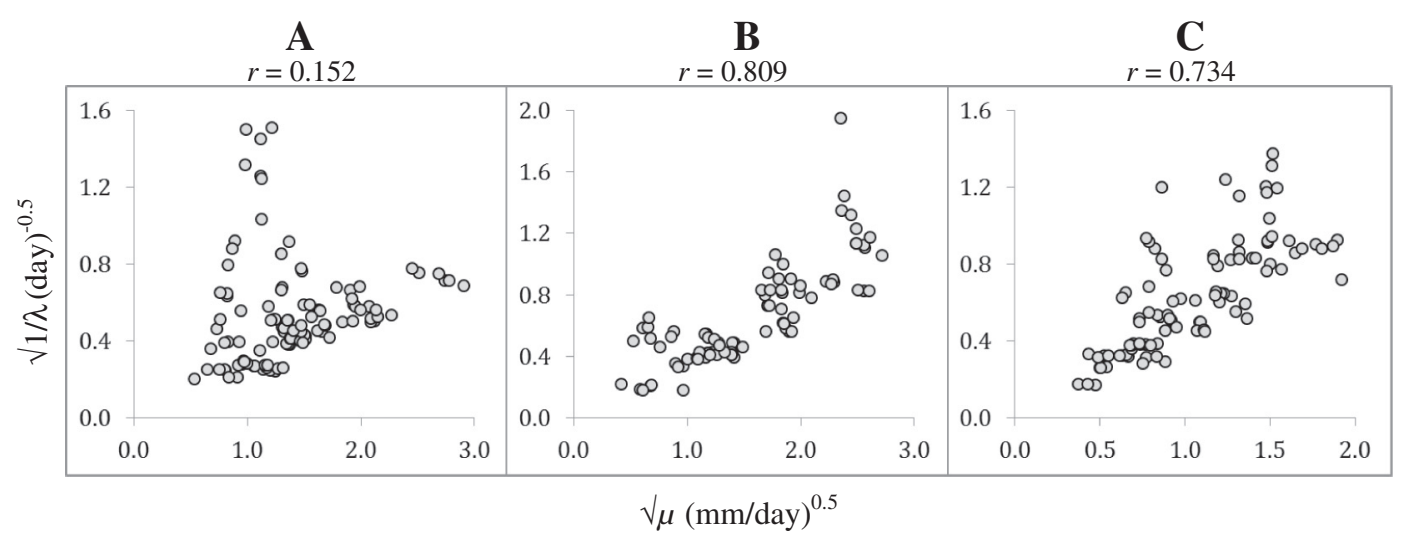

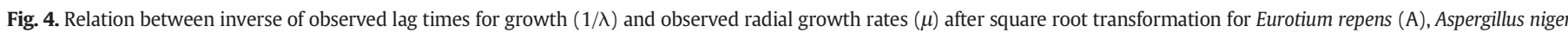
(B) and Penicillium corylophilum (C) with their correlation coefficients $(r)$. 
Table 7

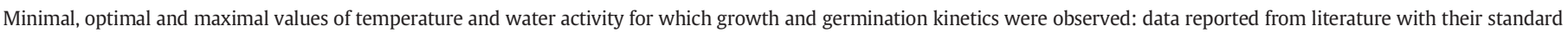
deviations (sd) when available. n.a.: not available; $\lambda$ : lag time for mycelium growth and $\mu$ : mycelium radial growth rate.

\begin{tabular}{|c|c|c|c|c|c|c|c|c|c|}
\hline Species & $\begin{array}{l}T_{\min }(\mathrm{sd}) \\
{ }^{\circ} \mathrm{C}\end{array}$ & $\begin{array}{l}T_{\text {opt }}(\mathrm{sd}) \\
{ }^{\circ} \mathrm{C}\end{array}$ & $\begin{array}{l}T_{\max }(\mathrm{sd}) \\
{ }^{\circ} \mathrm{C}\end{array}$ & $\begin{array}{l}a_{\mathrm{w} \min } \\
(\mathrm{sd})\end{array}$ & $\begin{array}{l}a_{\mathrm{w} \text { opt }} \\
(\mathrm{sd})\end{array}$ & $a_{\mathrm{w}}$ depressant & Kinetic response & Comment & Reference \\
\hline \multirow[t]{12}{*}{$\begin{array}{l}\text { Aspergillus } \\
\text { niger }\end{array}$} & $<10$ & n.a. & n.a. & n.a. & $0.98-0.995$ & Glycerol or glucose & Growth & $\begin{array}{l}\text { Derived from } \\
\text { observations }\end{array}$ & (Bellı et al., 2004) \\
\hline & $10.7(0.8)$ & $34.3(1.3)$ & n.a. & n.a. & n.a. & None & $\mu$ & $\begin{array}{l}\text { Secondary model } \\
\text { estimates }\end{array}$ & (Cuppers et al., 1997) \\
\hline & $10.1(0.3)$ & $31.4(0.2)$ & $43.1(0.1)$ & n.a. & n.a. & None & $\mu$ & $\begin{array}{l}\text { Secondary model } \\
\text { estimates }\end{array}$ & $\begin{array}{l}\text { (Gougouli and } \\
\text { Koutsoumanis, 2010) }\end{array}$ \\
\hline & $6.8(0.6)$ & $33.4(0.3)$ & $47.1(0.4)$ & n.a. & n.a. & None & $\lambda$ & $\begin{array}{l}\text { Secondary model } \\
\text { estimates }\end{array}$ & $\begin{array}{l}\text { (Gougouli and } \\
\text { Koutsoumanis, 2010) }\end{array}$ \\
\hline & $7.5(1.4)$ & $33.8(0.5)$ & $44.3(0.7)$ & n.a. & n.a. & None & Germination rate & $\begin{array}{l}\text { Secondary model } \\
\text { estimates }\end{array}$ & $\begin{array}{l}\text { (Gougouli and } \\
\text { Koutsoumanis, 2012) }\end{array}$ \\
\hline & $4.0(1.1)$ & $36.7(0.3)$ & $44.5(0.6)$ & n.a. & n.a. & None & $\begin{array}{l}\text { Lag time for } \\
\text { germination }\end{array}$ & $\begin{array}{l}\text { Secondary model } \\
\text { estimates }\end{array}$ & $\begin{array}{l}\text { (Gougouli and } \\
\text { Koutsoumanis, 2012) }\end{array}$ \\
\hline & $9.6(0.6)$ & $34.0(0.3)$ & $46.9(1.0)$ & n.a. & n.a. & None & $\mu$ & $\begin{array}{l}\text { Secondary model } \\
\text { estimates }\end{array}$ & (Gougouli et al., 2011) \\
\hline & $6.6(0.8)$ & $35.8(0.3)$ & $48.0(1.6)$ & n.a. & n.a. & None & $\lambda$ & $\begin{array}{l}\text { Secondary model } \\
\text { estimates }\end{array}$ & (Gougouli et al., 2011) \\
\hline & $6-8$ & $35-37$ & $45-47$ & n.a. & n.a. & None & Growth & $\begin{array}{l}\text { Derived from } \\
\text { observations }\end{array}$ & (Panasenko, 1967) \\
\hline & n.a. & 35 & n.a. & n.a. & $\geq 0.98$ & Glycerol & $\mu$ & $\begin{array}{l}\text { Derived from } \\
\text { observations }\end{array}$ & (Leong et al., 2006) \\
\hline & 8 & n.a. & n.a. & n.a. & n.a. & None & Growth & $\begin{array}{l}\text { Derived from } \\
\text { observations }\end{array}$ & $\begin{array}{l}\text { (Palacios-Cabrera et al., } \\
2005 \text { ) }\end{array}$ \\
\hline & n.a. & n.a. & n.a. & 0.77 & n.a. & Agar-cellulose strip & Growth & $\begin{array}{l}\text { Derived from } \\
\text { observations }\end{array}$ & (Ayerst, 1969) \\
\hline \multirow[t]{7}{*}{$\begin{array}{l}\text { Eurotium } \\
\text { repens }\end{array}$} & $4-5$ & $25-27$ & $\begin{array}{l}35-37 \text { and } \\
38-40\end{array}$ & n.a. & n.a. & None & Growth & $\begin{array}{l}\text { Derived from } \\
\text { observations }\end{array}$ & (Panasenko, 1967) \\
\hline & 7 & 24 & 38 & 0.71 & 0.93 & Agar-cellulose strip & Growth & $\begin{array}{l}\text { Derived from } \\
\text { observations }\end{array}$ & (Ayerst, 1969) \\
\hline & n.a. & n.a. & n.a. & 0.831 & n.a. & $\mathrm{NaCl}$ & Germination & $\begin{array}{l}\text { Derived from } \\
\text { observations }\end{array}$ & (Andrews and Pitt, 1987) \\
\hline & n.a. & n.a. & n.a. & 0.721 & n.a. & Glycerol & Germination & $\begin{array}{l}\text { Derived from } \\
\text { observations }\end{array}$ & (Andrews and Pitt, 1987) \\
\hline & n.a. & n.a. & n.a. & 0.685 & n.a. & Glucose/fructose & Germination & $\begin{array}{l}\text { Derived from } \\
\text { observations }\end{array}$ & (Andrews and Pitt, 1987) \\
\hline & n.a. & n.a. & n.a. & 0.70 & n.a. & Glucose/fructose & Germination & $\begin{array}{l}\text { Derived from } \\
\text { observations }\end{array}$ & (Gock et al., 2003) \\
\hline & n.a. & n.a. & n.a. & 0.74 & n.a. & Glucose/fructose & Growth & $\begin{array}{l}\text { Derived from } \\
\text { observations }\end{array}$ & (Gock et al., 2003) \\
\hline \multirow[t]{4}{*}{$\begin{array}{l}\text { Penicillium } \\
\text { corylophilum }\end{array}$} & n.a. & n.a. & n.a. & $\geq 0.80$ & n.a. & Glycerol & Growth & $\begin{array}{l}\text { Derived from } \\
\text { observations }\end{array}$ & (Abellana et al., 2001) \\
\hline & n.a. & n.a. & n.a. & $<0.85$ & n.a. & Glycerol & Growth & $\begin{array}{l}\text { Derived from } \\
\text { observations }\end{array}$ & (Marín et al., 2002a) \\
\hline & n.a. & n.a. & n.a. & $\geq 0.80$ & n.a. & $\begin{array}{l}\text { Cake analogue } \\
\text { and water }\end{array}$ & Growth & $\begin{array}{l}\text { Derived from } \\
\text { observations }\end{array}$ & (Marín et al., 2002b) \\
\hline & n.a. & n.a. & 37 & n.a. & n.a. & None & Growth & $\begin{array}{l}\text { Derived from } \\
\text { observations }\end{array}$ & (Pitt and Hocking, 2009) \\
\hline
\end{tabular}

In conclusion, the effect of $a_{\mathrm{w}}$, temperature, and $\mathrm{pH}$ on growth (lag time for mycelium growth and mycelium radial growth rate) of three molds isolated from spoiled bakery products has been quantitatively assessed. It was demonstrated that the same model structure can be applied to describe the temperature effect on mold growth whatever the species. In contrast, the effect of $a_{\mathrm{w}}$ on E. repens mycelium growth differed from the two other species. Further investigation would be necessary to draw a definitive conclusion on the potential relationship between lag time and growth rate; at this stage, it seems cautious to keep modeling these two responses separately when assessing product shelf-life.

\section{Acknowledgements}

The authors would like to acknowledge the LUBEM for providing the mold strains. The authors are also grateful to the Regions Pays de La Loire, Bretagne and Basse-Normandie through the "Pôle Agronomique Ouest" for their financial support in the framework of the ACIPPEV project.

\section{Appendix A. Supplementary data}

Supplementary data to this article can be found online at http://dx. doi.org/10.1016/j.ijfoodmicro.2014.06.022.

\section{References}

Abellana, M., Benedí, J., Sanchis, V., Ramos, A.J., 1999. Water activity and temperature effects on germination and growth of Eurotium amstelodami, E. chevalieri and $E$. herbariorum isolates from bakery products. J. Appl. Microbiol. 87, 371-380.

Abellana, M., Sanchis, V., Ramos, A.J., 2001. Effect of water activity and temperature on growth of three Penicillium species and Aspergillus flavus on a sponge cake analogue. Int. J. Food Microbiol. 71, 151-157.

Andrews, S., Pitt, J.I., 1987. Further studies on the water relations of xerophilic fungi, including some halophiles. J. Gen. Microbiol. 133, 233-238.

Astoreca, A., Vaamonde, G., Dalcero, A., Ramos, A., Marín, S., 2012. Modelling the effect of temperature and water activity of Aspergillus flavus isolates from corn. Int. J. Food Microbiol. 156, 60-67.

Ayerst, G., 1969. The effects of moisture and temperature on growth and spore germination in some fungi. J. Stored Prod. Res. 5, 127-141.

Baranyi, J., Csernus, O., Beczner, J., 2014. Error analysis in predictive modelling demonstrated on mould data. Int. J. Food Microbiol. 170, 78-82.

Baty, F., Delignette-Muller, M.-L., 2012. nlstools: tools for nonlinear regression diagnostics. 
Belli, N., Maŕn, S., Sanchis, V., Ramos, A.J., 2004. Influence of water activity and temperature on growth of isolates of Aspergillus section Nigri obtained from grapes. Int. J. Food Microbiol. 96, 19-27.

Berg, A., Meyer, R., Yu, J., 2004. Deviance information criterion for comparing stochastic volatility models. J. Bus. Econ. Stat. 22, 107-120.

Buchanan, R.L., Whiting, R.C., Damert, W.C., 1997. When is simple good enough: a comparison of the Gompertz, Baranyi, and three-phase linear models for fitting bacterial growth curves. Food Microbiol. 14, 313-326.

Cuppers, H.G., Oomes, S., Brul, S., 1997. A model for the combined effects of temperature and salt concentration on growth rate of food spoilage molds. Appl. Environ. Microbiol. 63, 3764-3769.

Dagnas, S., Membré, J.-M., 2013. Predicting and preventing mold spoilage of food products. J. Food Prot. 76, 538-551.

Dakins, M.E., Toll, J.E., Small, M.J., Brand, K.P., 1996. Risk-based environmental remediation: Bayesian Monte Carlo analysis and the expected value of sample information. Risk Anal. 16, 67-79.

Dantigny, P., Bensoussan, M., 2008. The logarithmic transformation should be avoided for stabilising the variance of mould growth rate. Int. J. Food Microbiol. 121, 225-228.

Dantigny, P., Guilmart, A., Bensoussan, M., 2005a. Basis of predictive mycology. Int. J. Food Microbiol. 100, 187-196.

Dantigny, P., Guilmart, A., Radoi, F., Bensoussan, M., Zwietering, M., 2005b. Modelling the effect of ethanol on growth rate of food spoilage moulds. Int. J. Food Microbiol. 98, 261-269.

Dantigny, P., Bensoussan, M., Vasseur, V., Lebrihi, A., Buchet, C., Ismaili-Alaoui, M., Devlieghere, F., Roussos, S., 2006. Standardisation of methods for assessing mould germination: a workshop report. Int. J. Food Microbiol. 108, 286-291.

d'Enfert, C., 1997. Fungal spore germination: insights from the molecular genetics of Aspergillus nidulans and Neurospora crassa. Fungal Genet. Biol. 21, 163-172.

Deschuyffeleer, N., Samapundo, S., Devlieghere, F., 2013. Secondary models for fungi. In: Dantigny, P., Panagou, E.Z. (Eds.), Predictive Mycology. Nova Science Publishers, Inc., pp. 153-194.

Garcia, D., Ramos, A.J., Sanchis, V., Marín, S., 2009. Predicting mycotoxins in foods: a review. Food Microbiol. 26, 757-769.

Garcia, D., Ramos, A.J., Sanchis, V., Marín, S., 2011. Modelling the effect of temperature and water activity in the growth boundaries of Aspergillus ochraceus and Aspergillus parasiticus. Food Microbiol. 28, 406-417.

Gock, M.A., Hocking, A.D., Pitt, J.I., Poulos, P.G., 2003. Influence of temperature, water activity and $\mathrm{pH}$ on growth of some xerophilic fungi. Int. J. Food Microbiol. 81, 11-19.

Gougouli, M., Koutsoumanis, K.P., 2010. Modelling growth of Penicillium expansum and Aspergillus niger at constant and fluctuating temperature conditions. Int. J. Food Microbiol. 140, 254-262.

Gougouli, M., Koutsoumanis, K.P., 2012. Modeling germination of fungal spores at constant and fluctuating temperature conditions. Int. J. Food Microbiol. 152, 153-161.

Gougouli, M., Koutsoumanis, K.P., 2013. Relation between germination and mycelium growth of individual fungal spores. Int. J. Food Microbiol. 161, 231-239.

Gougouli, M., Kalantzi, K., Beletsiotis, E., Koutsoumanis, K.P., 2011. Development and application of predictive models for fungal growth as tools to improve quality control in yogurt production. Food Microbiol. 28, 1453-1462.

Hocking, A.D., Pitt, J.I., 1980. Dichloran-glycerol medium for enumeration of xerophilic fungi from low-moisture foods. Appl. Environ. Microbiol. 39, 488-492.

Horner, K.J., Anagnostopoulos, G.D., 1973. Combined effects of water activity, pH and temperature on the growth and spoilage potential of fungi. J. Appl. Microbiol. 36, 427-436.

Huchet, V., Pavan, S., Lochardet, A., Divanac'h, M.L., Postollec, F., Thuault, D., 2013. Development and application of a predictive model of Aspergillus candidus growth as a tool to improve shelf life of bakery products. Food Microbiol. 36, 254-259.

Judet-Correia, D., Bollaert, S., Duquenne, A., Charpentier, C., Bensoussan, M., Dantigny, P. 2010. Validation of a predictive model for the growth of Botrytis cinerea and Penicillium expansum on grape berries. Int. J. Food Microbiol. 142, 106-113.

Leistner, L., 2000. Basic aspects of food preservation by hurdle technology. Int. J. Food Microbiol. 55, 181-186.

Leong, S.-L.L., Hocking, A.D., Scott, E.S., 2006. Effect of temperature and water activity on growth and ochratoxin A production by Australian Aspergillus carbonarius and A. niger isolates on a simulated grape juice medium. Int. J. Food Microbiol. 110, 209-216.

Lunn, D.J., Thomas, A., Best, N., Spiegelhalter, D., 2000. WinBUGS - A Bayesian modelling framework: concepts, structure, and extensibility. Stat. Comput. 10, 325-337.

Malkki, Y., Ravha, O., 1978. Mold inhibition by aerosols. Baker's Dig 52 (1), 47-50.

Marin, J.-M., Robert, C., 2007. A Bayesian core: a practical approach to computational Bayesian statistics. Springer.

Marín, S., Sanchis, V., Teixido, A., Saenz, R., Ramos, A.J., Vinas, I., Magan, N., 1996. Water and temperature relations and microconidial germination of Fusarium moniliforme and Fusarium proliferatum from maize. Can. J. Microbiol. 42.
Marín, S., Guynot, M.E., Neira, P., Bernado, M., Sanchis, V., Ramos, A.J., 2002a. Risk assessment of the use of sub-optimal levels of weak-acid preservatives in the control of mould growth on bakery products. Int. J. Food Microbiol. 79, 203-211.

Marín, S., Guynot, M.E., Sanchis, V., Arbonés, J., Ramos, A.J., 2002b. Aspergillus flavus, Aspergillus niger, and Penicillium corylophilum spoilage prevention of bakery products by means of weak-acid preservatives. J. Food Sci. 67, 2271-2277.

Marín, S., Colom, C., Sanchis, V., Ramos, A.J., 2009. Modelling of growth of aflatoxigenic A flavus isolates from red chilli powder as a function of water availability. Int. J. Food Microbiol. 128, 491-496.

Mertens, L., Van Derlinden, E., Van Impe, J.F., 2012. Comparing experimental design schemes in predictive food microbiology: optimal parameter estimation of secondary models. J. Food Eng. 112, 119-133.

Mitra, D., 2013. Likelyhood inference for left truncated and right censored lifetime data(PhD thesis) McMaster University.

Nanguy, S.P.-M., Perrier-Cornet, J.-M., Bensoussan, M., Dantigny, P., 2010. Impact of water activity of diverse media on spore germination of Aspergillus and Penicillium species. Int. J. Food Microbiol. 142, 273-276.

Nevarez, L., Vasseur, V., Le Madec, A., Le Bras, M.A., Coroller, L., Leguérinel, I., Barbier, G., 2009. Physiological traits of Penicillium glabrum strain LCP 08.5568, a filamentous fungus isolated from bottled aromatised mineral water. Int. J. Food Microbiol. 130, $166-171$.

Palacios-Cabrera, H., Taniwaki, M.H., Hashimoto, J.M., de Menezes, H.C. 2005. Growth of Aspergillus ochraceus, A. carbonarius and A. niger on culture media at different water activities and temperatures. Braz. J. Microbiol. 36, 24-28.

Panagou, E.Z., Skandamis, P.N., Nychas, G.-J.E., 2003. Modelling the combined effect of temperature, $\mathrm{pH}$ and aw on the growth rate of Monascus ruber, a heat-resistant fungus isolated from green table olives. J. Appl. Microbiol. 94, 146-156.

Panasenko, V.T., 1967. Ecology of microfungi. Bot. Rev. 33, 189-215.

Parra, R., Magan, N., 2004. Modelling the effect of temperature and water activity on growth of Aspergillus niger strains and applications for food spoilage moulds. J. Appl. Microbiol. 97, 429-438.

Patwardhan, A., Small, M.J., 1992. Bayesian methods for model uncertainty analysis with application to future sea level rise. Risk Anal. 12, 513-523.

Pitt, J.I., Hocking, A.D., 1977. Influence of solute and hydrogen ion concentration on the water relations of some xerophilic fungi. J. Gen. Microbiol. 101, 35-40.

Pitt, J.I., Hocking, A.D., 2009. Penicillium and Related Genera, Fungi and Food Spoilage, 3rd ed. Springer-Verlag New York Inc., New York, NY/US, pp. 169-274.

Ratkowsky, D.A., 2004. Model fitting and uncertainty. In: McKellar, R.C., Lu, X. (Eds.) Modeling microbial responses in food. CRC Press, Boca Raton, pp. 151-196.

R-Development-Core-Team, 2012. In: R Foundation for Statistical Computing (Ed.), R: a language and environment for statistical computing, 2.15.00. R Development Core Team, Vienna, Austria.

Rosso, L., Robinson, T.P., 2001. A cardinal model to describe the effect of water activity on the growth of moulds. Int. J. Food Microbiol. 63, 265-273.

Rosso, L., Lobry, J.R., Bajard, S., Flandrois, J.P., 1995. Convenient model to describe the combined effects of temperature and $\mathrm{pH}$ on microbial growth. Appl. Environ. Microbiol. 61, 610-616.

Sautour, M., Dantigny, P., Divies, C., Bensoussan, M., 2001a. A temperature-type model for describing the relationship between fungal growth and water activity. Int. J. Food Microbiol. 67, 63-69.

Sautour, M., Rouget, A., Dantigny, P., Divies, C., Bensoussan, M., 2001b. Application of Doehlert design to determine the combined effects of temperature, water activity and $\mathrm{pH}$ on conidial germination of Penicillium chrysogenum. J. Appl. Microbiol. 91 900-906.

Tassou, C.C., Panagou, E.Z., Natskoulis, P., Magan, N., 2007. Modelling the effect of temperature and water activity on the growth of two ochratoxigenic strains of Aspergillus carbonarius from Greek wine grapes. J. Appl. Microbiol. 103, 2267-2276.

Van Derlinden, E., Mertens, L., Van Impe, J.F., 2013. The impact of experiment design on the parameter estimation of cardinal parameter models in predictive microbiology Food Control 29, 300-308.

Vytrasova, J., Pribanova, P., Marvanova, L., 2002. Occurrence of xerophilic fungi in bakery gingerbread production. Int. J. Food Microbiol. 72, 91-96.

Wheeler, K.A., Hurdman, B.F., Pitt, J.I., 1991. Influence of pH on the growth of some toxigenic species of Aspergillus, Penicillium and Fusarium. Int. J. Food Microbiol. 12, 141-149.

Zwietering, M.H., Wijtzes, T., Rombouts, F.M., van't Riet, K., 1993. A decision support system for prediction of microbial spoilage in foods. J. Ind. Microbiol. Biotechnol. 12, 324-329.

Zwietering, M.H., de Wit, J.C., Notermans, S., 1996. Application of predictive microbiology to estimate the number of Bacillus cereus in pasteurised milk at the point of consumption. Int. J. Food Microbiol. 30, 55-70. 